\title{
UMA INFRAESTRUTURA MUÇULMANA DE CHEGADA NO RIO DE JANEIRO
}

\author{
A Muslim arrival infrastructure in Rio de Janeiro
}

Tilmann Heil*

Resumo. Nos últimos dez anos, uma dahira, coletivo religioso de migrantes senegaleses, surgiu e se desenvolveu no Estado do Rio de Janeiro. Acompanhei seu singular processo de institucionalização e a maneira como ela chegou a fazer parte das redes internacionais dessa confraria religiosa. Neste artigo, discuto como a dahira se tornou uma infraestrutura de chegada no contexto específico do Rio de Janeiro e comparo as iniciativas do coletivo da dahira com outras estruturas senegalesas, evidenciando a complexidade das relações sócio-materiais entre os senegaleses.

Palavras-chave: infraestrutura de chegada; murids, migração; cidade; Rio de Janeiro.

\begin{abstract}
For ten years, a dahira, a religious group of Senegalese migrants in the State of Rio de Janeiro has grown. I accompanied the unique process of how this Murid dahira was institutionalised and became part of the international network of the brotherhood. I discuss how the dahira became an arrival infrastructure in the specific context of Rio de Janeiro and I compare its initiatives with parallel Senegalese structures. This shows the complexity of the socio-material relations among the Senegalese.
\end{abstract}

Keywords: arrival infrastructure; Murids; migration; city; Rio de Janeiro.

Universidade de Leuven, Bélgica (FWO [PEGASUS] ${ }^{2}$ Marie Skłodowska-Curie Fellow)/ Universidade Federal do Rio de Janeiro. Rio de Janeiro, RJ, Brasil. 


\section{Introdução ${ }^{1}$}

Desde 2014, acompanhei a presença recente e flutuante da comunidade senegalesa na Região Metropolitana do Rio de Janeiro². Esta reflexão sobre a infraestrutura muçulmana de chegada no Rio de Janeiro, que tem como base minha convivência com esse coletivo, oferece uma complementação aos estudos sobre o transnacionalismo e sobre o comércio e a religião muçulmana relativos à imigração senegalesa no sul do Brasil, em São Paulo e em outras localidades ${ }^{3}$. Há aspectos dessa migração e de suas redes transnacionais que já foram pesquisados em vários países do mundo ${ }^{4}$. Porém, defendo neste artigo que existem particularidades da experiência e do desenvolvimento da presença senegalesa no Rio de Janeiro. Considerando a relativa ausência de instituições relevantes para os recém-chegados nessa localidade, essas particularidades são mais bem entendidas a partir de sua infraestrutura. Acompanhei o singular processo de crescimento e institucionalização de uma dahira da confraria murid no Rio de Janeiro e como ela chegou a fazer parte de suas redes internacionais e da circulação dos marabouts, seus guias religiosos. Também discuto como a dahira se tornou parte de uma infraestrutura de chegada no contexto específico do Rio de Janeiro, tanto durante os megaeventos de alguns anos atrás (e.g. Copa do Mundo de 2014 e Olimpíada de 2016) quanto durante a crise econômica atual. Comparo as iniciativas do coletivo da dahira murid com estruturas senegalesas paralelas que mostram a complexidade das relações sociais entre senegaleses e os projetos e táticas particulares de cada migrante. Uso o material etnográfico que obtive entre 2014 e 2017 por meio de observação participante e de conversas e entrevistas com membros da dahira e com outros senegaleses na região.

Sigo a proposta teórica dos trabalhos mais recentes sobre infraestruturas sociais e urbanas e de migração ${ }^{5}$. Tenho especial interesse nas infraestruturas de chegada ${ }^{6}$, ou seja, as constelações de atores, instituições e tecnologias que interagem quando pessoas chegam a um espaço urbano. Essa literatura marca novos desenvolvimentos e uma nova dinâmica na antropologia urbana: "We

1 This project has received funding from the European Union's Horizon 2020 research and innovation programme under the Marie Skłodowska-Curie grant agreement No 665501 with the research Foundation Flanders (FWO).

2 Como a principal forma de permanência de senegaleses no território brasileiro está baseada em pedidos de refúgio, o número de 7.206 solicitantes senegaleses entre 2010-2015 fornece uma noção geral dessa imigração. Cf. COMITÊ NACIONAL PARA OS REFUGIADOS. Sistema de Refúgio brasileiro, p. 5.

3 TEDESCO, João Carlos, KLEIDERMACHER, Giselle. A imigração senegalesa no Brasil e na Argentina; HERÉDIA, Vania Beatriz Merlotti. Migrações internacionais.

4 CARTER, Donald Martin. States of grace; DIOUF, Mamadou. The Senegalese Murid trade diaspora and the making of a vernacular cosmopolitanism; RICCIO, Bruno. Transnational Mouridism and the Afro-Muslim critique of Italy.

5 GRAHAM, Stephen, MCFARLANE, Colin. Infrastructural lives; XIANG, Biao, LINDQUIST, Johan. Migration Infrastructure.

6 MEEUS, Bruno, KAREL, Arnaut, VAN HEUR, Bas. Arrival infrastructures. 
are seeing the rise of a new genre of thinking that narrates the social life of a city through its material infrastructure ${ }^{\prime \prime}$. Além disso, essa abordagem desenvolveu-se em grande medida a partir de cidades do hemisfério sul ${ }^{8}$. Veremos que, em lugar de se restringirem à perspectiva da infraestrutura material, os autoreschave dessa abordagem se inscrevem nas tradições teóricas que tratam das constelações dinâmicas das quais fazem parte elementos humanos e não humanos, típicas da proposta teórica original do agenciamento.

Em segundo lugar, contribuo com a discussão sobre as relações entre migração e cidade . Proponho que devemos entender os migrantes como residentes recém-chegados em vez de percebê-los como estrangeiros, "Outros", ou aqueles que não pertencem. Porém, um certo estranhamento dentro do mesmo espaço urbano pode ser mantido. É válido abordar a vida de recémchegados a partir da literatura sobre os marginalizados, subalternos, excluídos e não cidadãos do espaço urbano já existente ${ }^{10}$. Assim não continuarei com o excepcionalismo da migração que problematiza o migrante e o fenômeno da migração, esquecendo-se das relações dinâmicas em toda a gama de mobilidades e imobilidades ${ }^{11}$. Ainda assim, mantenho uma perspectiva crítica sobre o poder e sobre as relações de desigualdade.

A partir dessas duas considerações, apresentarei a crescente presença e participação dos residentes recém-chegados do Senegal na vida urbana e uma de suas formas mais centrais de organização, e por isso, a mais analisada e discutida. Dahira ou daira significa círculo, uma associação local de membros da confraria murid. É uma forma de organização onipresente no mundo dos senegaleses, com exemplos muito bem estudados na Itália e nos Estados Unidos $^{12}$. É um lugar de encontro, de oração e recitação dos poemas do guia murid Cheikh Ahmadou Bamba Mbacké, mas também de prestação de apoio mútuo, de troca de informações e até de interações comerciais.

O caso da dahira da Região Metropolitana do Rio de Janeiro, com sede em Niterói (a segunda maior municipalidade da região), me ofereceu a possibilidade de acompanhar, a partir de 2014, o processo de crescimento e de maturação dessa estrutura já conhecida em um novo contexto. Com isso,

\footnotetext{
AMIN, Ash. Lively Infrastructure, p. 137.

8 SIMONE, AbdouMaliq. People as Infrastructure; MCFARLANE, Colin. The city as assemblage; DE BOECK, Filip, BALOJI Sammy. Suturing the City.

9 ABREU, Maurício de A. Evolução urbana do Rio de Janeiro; OLIVEN, Ruben George. Urbanização e mudança social no Brasil; PAIVA, Odair da Cruz. Territórios da migração na cidade de São Paulo; GLICK SCHILLER, Nina, ÇAĞLAR, Ayşe. Locating migration. Rescaling cities and migrants; LANDAU, Loren B. Conviviality, Rights, and Conflict in Africa's Urban Estuaries; VERTOVEC, Steven. Diversities old and new; MEEUS, KAREL, VAN HEUR, op. cit.

${ }^{10}$ Cf. contribuições em GRAHAM, MCFARLANE, op. cit.; AMIN, op. cit.

${ }^{11} \mathrm{HUI}$, Allison. The Boundaries of Interdisciplinary Fields.

${ }^{12}$ CARTER, op. cit.; DIOUF, op. cit.; BABOU, Cheikh Anta. Brotherhood solidarity, education and migration; RICCIO, op. cit.; IDEM. "Transmigrants" mais pas "nomades".
} 
é possível apresentar um retrato conciso da chegada senegalesa na Região Metropolitana do Rio de Janeiro e avaliar o funcionamento da dahira como parte de uma infraestrutura de chegada.

Fundada há 10 anos com o nome Norou Darayni, termo árabe para "claridade aqui e lá", essa dahira foi a primeira do Brasil. Nos primeiros anos, ela teve um crescimento lento, mas passou a se desenvolver mais rapidamente nos últimos quatro anos, em coincidência com os megaeventos ocorridos na cidade. Apesar das crises no país, no Estado e na cidade, a dahira Norou Darayni continuou a crescer. Esse crescimento se confirmou pela identificação dos vários espaços físicos ocupados ao longo dos anos pela dahira. Ela começou em um quarto da casa de um dos primeiros cinco membros fundadores e hoje ocupa um espaço de aproximadamente $100 \mathrm{~m}^{2}$. É constituída por uma grande sala, dois quartos, cozinha e área de serviço. O salão é o local de reunião, capaz de acolher mais de cem pessoas. Um dos quartos se destina à moradia permanente de três a quatro pessoas que trabalham como cuidadores do espaço. Outro quarto serve para hospedar "estrangeiros", principalmente líderes religiosos. A dahira é dirigida pelo dieuwrigne ${ }^{13}$, seu responsável, e por um comitê eleito.

É impossível saber quantos membros a dahira tem atualmente. Constatou-se uma dinâmica extraordinária, pois a maioria eram vendedores ambulantes que circulavam diariamente no Rio de Janeiro, em outras cidades brasileiras e também na Argentina. Na base desse movimento estão as redes pessoais e as ofertas de trabalho variadas nos distintos lugares. No entanto, foi possível perceber uma participação de senegaleses cada vez maior nos encontros semanais e eventos religiosos organizados pela dahira, sinalizando seu crescimento. A celebração do màggal de 2017 foi o ponto alto do ano, com a participação ativa de mais de 300 senegaleses.

Discutirei o màggal e a primeira vinda em 2016 de um líder religioso importante da diáspora senegalesa como exemplos da infraestrutura de chegada senegalesa muçulmana dos últimos dois anos. Apresentarei então minha abordagem teórica em mais profundidade antes de analisar a dinâmica da infraestrutura muçulmana de chegada a partir da dahira. A seguir, tratarei das interdependências polivalentes existentes na infraestrutura e sua dimensão virtual. Por fim, oferecerei conclusões sobre o potencial de se abordar a chegada de novos residentes em uma cidade como o Rio de Janeiro por meio do conceito de infraestrutura de chegada.

${ }^{13}$ Dieuwrigne é uma palavra wolof que se refere ao responsável da dahira. Ele é o representante e o responsável moral da instituição perante as autoridades religiosas. No cotidiano, ele se ocupa das questões práticas do coletivo, diferente dos marabouts, que se dedicam à religião. 


\section{Conceituar infraestrutura de chegada}

Chamar algo de infraestrutura é um ato de categorização, porque uma de suas características é que não se pode definir facilmente onde ela começa ou termina ${ }^{14}$. É preciso, portanto, saber como o conceito tem sido usado nos últimos anos para discutir o desenvolvimento das cidades emergentes, as dinâmicas da migração e as questões de chegada. Seguem esses três aspectos.

\section{Infraestrutura e cidade}

A abordagem das infraestruturas é tributária de trabalhos inspirados na obra de Deleuze e Guatarri ${ }^{15}$, críticos das visões da sociedade como totalidade ${ }^{16}$. No lugar disso, a teoria do ator-rede ou a teoria do agenciamento (assemblage) propõe uma abordagem que permite entender a complexidade social a partir de sua dinâmica e fluidez. Um de seus autores centrais, o filósofo mexicano Manuel DaLanda, constrói uma visão ontológica de agenciamento a partir das relações extrínsecas entre elementos constituintes dessas composições e dos processos relacionados de territorialização e desterritorialização. Vale recorrer à definição básica que abre uma recente publicação do autor:

The word in English fails to capture the meaning of the original agencement, a term that refers to the action of matching or fitting together a set of components (agencer), as well as to the result of such an action: an ensemble of parts that mesh together well. ${ }^{17}$

É nesse campo teórico que a abordagem das infraestruturas se situa. Precisamos lembrar que os elementos das composições podem ser humanos ou não e, em vez de se encontrarem restritos a um agenciamento (que seria o caso das teorias da totalidade, principalmente hegelianas), podem fazer parte de várias composições e escalas diferentes ${ }^{18}$.

Em seu trabalho sobre infraestruturas vivas (lively infrastructures) com colaboradores em Belo Horizonte, Ash Amin propõe novas formas de entender e trabalhar com as realidades das populações marginais nas cidades em crescimento. Os autores procuram realizar uma análise dos serviços mais básicos como saneamento, luz e moradia acessível nas favelas e regiões periféricas da capital mineira. Observando a interação das pessoas com as infraestruturas urbanas, Amin constata:

Accordingly, both the social and the technological are imagined as hybrids of human and nonhuman association, with infrastructure conceptualized as

\footnotetext{
${ }^{14}$ LARKIN, Brian. The Politics and Poetics of Infrastructure.

${ }^{15}$ DELEUZE, Gilles, GUATTARI, Félix. A thousand plateaus. Cf. DELANDA, Manuel. A new philosophy of society, 3, nota de rodapé 3 .

${ }^{16}$ Cf. Ibidem, p. 8-25.

17 IDEM. Assemblage theory, p. 1.

${ }^{18}$ Cf. IDEM. A new philosophy..., op. cit., p. 8-25.
} 
a sociotechnical assemblage, and urban social life as never reducible to the purely human alone. ${ }^{19}$

Lembramos três aspectos centrais dessa nova abordagem. Primeiro, qualquer infraestrutura material é não só técnica como também social; segundo, é preciso considerar as dimensões simbólicas e a seletividade social das infraestruturas; e terceiro, as infraestruturas - sejam elas visíveis ou não, complexas ou simples -, têm implicações para as experiências humanas nas cidades e para a formação de identidades sociais ${ }^{20}$. Consequentemente, hoje entendemos infraestruturas como "a socio-technical process with diverse agentive powers" ${ }^{21}$.

Uma proposta ainda mais voltada para o social vem do antropólogo afro-americano AbdouMaliq Simone, que estuda como as próprias pessoas podem se tornar infraestrutura e como relações sociais podem ser estudadas a partir dessa perspectiva. Sobre relações sociais, ele comenta:

they are materials themselves to be articulated in various forms in order to construct circulations of bodies, resources, affect and information. They are vehicles of movement and becoming, ways of mediating the constantly oscillating intersections of various times, spaces, economies, constraints and possibilities making up city life. Relations are also the tools through which political imaginations and claims are exerted and thus are the embodiment of force. ${ }^{22}$

Observadas em contextos urbanos africanos e asiáticos, campo estudado por Simone, essas infraestruturas relacionais permitem pensar relações sóciomateriais por meio das qualidades que a nova perspectiva da infraestrutura define.

\section{Infraestrutura de migração}

Biao Xiang e Johan Lindquist seguem essa proposta e a aplicam ao caso da migração. Buscam uma maneira de falar da forte intermediação presente na migração e vão além de uma investigação das redes dos migrantes, das políticas migratórias e/ou do mercado de trabalho que geralmente são considerados nas análises da migração. Para eles a perspectiva da infraestrutura permite mostrar as mediações sistemáticas entre a tecnologia, as instituições e atores, que facilitam e condicionam a i/mobilidade. Para os autores, migração

is rather constituted by a multitude of activities, practices, and technologies that must be considered in specific contexts. Migration infrastructure

\footnotetext{
${ }^{19}$ AMIN, op. cit., $137 f$.

20 TONKISS, Fran. Cities by design.

21 AMIN, op. cit., p. 139; HARVEY, Penelope. The topological quality of infrastructural relation.

${ }^{22}$ SIMONE, AbdouMaliq. Relational infrastructures in postcolonial urban worlds, p. 18.
} 
provides a framework that offers analytical order to these activities without assigning them to pre-given categories. ${ }^{23}$

Eles pesquisam cinco dimensões ou "lógicas de operação" da infraestrutura de migração: a comercial (recrutamento), a regulatória (Estado, regulação etc.), a tecnológica (comunicação e transporte), a humanitária (organizações não governamentais, organizações internacionais) e a social (migrantes) ${ }^{24}$. A partir disso, mostram como a infraestrutura é diferente de vários conceitos nos estudos migratórios. Ao mesmo tempo em que enfocam a mediação, Xiang e Lindquist são críticos ao uso do conceito sistema de migração, o que reificaria a mobilidade e não permitiria entender as instabilidades. Abordar o fenômeno com base em regimes de mobilidade, por sua vez, mostraria apenas como a mobilidade é estruturada e incorporada nas relações de poder hegemônicas, assim como a perspectiva de redes de migração constataria a existência destas, mas dificilmente colocaria a rede em si no centro da análise, algo que a perspectiva da infraestrutura consegue.

Seguindo esses autores, entende-se a linguagem da infraestrutura como uma perspectiva intermediária, que permite focar em realidades que antes passavam despercebidas na análise ${ }^{25}$.

\section{Infraestrutura de chegada}

A infraestrutura de chegada refere-se às definições das dinâmicas das cidades de chegada (arrival cities) e dos estuários urbanos (urban estuaries) ${ }^{26}$. Foi a partir do livro do jornalista Doug Saunders Arrival City que a questão da transformação e crescimento das cidades ocasionados pela migração rural foi colocada nesses termos. Saunders identificou que, mesmo com aparências físicas diferenciadas, esses espaços urbanos onde os novos residentes chegam têm funções básicas e redes de relações humanas específicas, porém globalmente parecidas. Apesar de serem espaços de possíveis conflitos e violência, Saunders enfatiza sua importância como lugares onde mudanças acontecem e onde a nova classe média e as futuras gerações crescem com suas aspirações, movimentos e ideias políticas.

Chamar a atenção para esses espaços urbanos é importante para entender os processos de chegada em cidades. Acredito, no entanto, que podemos complexificar essa proposta. Para isso, o estudo de Loren Landau sobre estuários urbanos nas cidades da África oferece um ponto de partida interessante. Diversos aspectos desse contexto parecem servir também ao caso

\footnotetext{
${ }^{23}$ XIANG, LINDQUIST, op. cit., S143. Cf. CRANSTON, Sophie, SCHAPENDONK, Joris, SPAAN, Ernst. New directions in exploring the migration industries.

${ }^{24}$ XIANG, LINDQUIST, op. cit., S124.

25 Ibidem, S142.

${ }^{26}$ SAUNDERS, Doug. Arrival city; LANDAU, op. cit.
} 
da imigração africana recente no Rio de Janeiro. Landau caracteriza estuários urbanos da seguinte forma:

The urban estuaries these movements create-meeting places of multiple human flows that remain largely unregulated by states or dominant social institutions-are at once unstable and fertile grounds. Much like natural estuaries where interactions between rivers and tides create uniquely dynamic ecosystems, these urban gateways generate distinct sociopolitical forms through the multiple movements and dynamics taking place within them. In these zones, cultural and linguistic heterogeneity are often empirical norms, not exceptions. ${ }^{27}$

Landau chama atenção à problemática desses espaços urbanos pouco controlados e, por isso, pouco compreendidos. Precárias e fluidas, as formas políticas e normativas emergentes nesses espaços precisam de muita análise para que se possa entender as conquistas e os fracassos dos projetos dos recémchegados em busca de um de futuro urbano melhor.

Com esse conjunto de considerações conceituais, a exploração da infraestrutura de chegada dos senegaleses muçulmanos oferece uma tentativa promissora para entender melhor alguns aspectos dessa situação de chegada complexa. Não podemos esquecer que as infraestruturas estatais de suporte à migração são precárias, o que mostra as desigualdades estruturais existentes. A ausência do Estado ${ }^{28}$ leva a um processo de autoconstrução que ocorre em grandes espaços da cidade e, como veremos, ocorrem também no contexto de chegada dos senegaleses. A abordagem conceitual proposta acima informa a estruturação do relato etnográfico a seguir e permite estruturá-lo claramente sem perda da complexidade e da multidirecionalidade encontradas no campo de estudo.

\section{A dinâmica da infraestrutura a partir da dahira}

Antes dos megaeventos, era pequena a rede de apoio para a chegada de alguém de nacionalidade senegalesa, ou mesmo de outra origem africana, à Região Metropolitana do Rio de Janeiro. Eventualmente, o recém-chegado era encaminhado ao consulado geral do Senegal, na avenida Rio Branco, onde os funcionários chamavam o dieuwrigne da dahira para tomar conta dessa pessoa. O dieuwrigne relata como resolvia, a partir desse momento, as necessidades urgentes, como hospedagem, nutrição e possivelmente uma inserção na venda ambulante. Ser o responsável da dahira facilitava sua atuação. Se alguém queria ficar, os membros da dahira tomavam conta dos passos administrativos. Começavam com o pedido de refúgio na Caritas, o meio de legalização mais comum dos recém-chegados africanos na cidade. Com o protocolo servindo como documentação, eles obtinham a carteira de trabalho e, assim, em tese,

\footnotetext{
27 Ibidem, p. 361.

${ }^{28}$ Cf. AMIN, op. cit., p. 155.
} 
acesso ao mercado de trabalho formalizado. Porém, o dieuwrigne relata que, naquela época, muitas vezes se tratava apenas de acolher alguém por poucos dias e depois comprar sua passagem para o Sul do país ou diretamente para Argentina, onde se esperavam melhores oportunidades.

Esse apoio foi fundamental até os megaeventos, que trouxeram um grande número de vendedores ambulantes em busca de oportunidades econômicas ${ }^{29}$. Hoje, o responsável da dahira explica que são raros os casos em que esse mecanismo ainda se mantém ativo. Atualmente, a realidade no Rio de Janeiro é outra: devido à crescente presença dos senegaleses na Região Metropolitana ao longo dos anos, cada vez mais os recém-chegados encontram facilmente alguém já enraizado na cidade para ajudá-los. Em geral, eles satisfazem assim as necessidades mais urgentes e organizam os primeiros passos a partir desse primeiro contato aleatório. Porém, se necessário, qualquer pessoa ou instituição consegue ativar os mecanismos que envolvem as outras partes da infraestrutura de chegada senegalesa no Rio de Janeiro, como o consulado ou a dahira. Ao longo do tempo em que convivi com essa infraestrutura, era na interação dessas duas formas de ativação da infraestrutura que se encontravam soluções para qualquer desafio apresentado. A infraestrutura se desenvolveu de forma independente das instituições estatais locais, porém em reação a sua ausência e em relação com as experiências transnacionais dos senegaleses.

Antes de caracterizar as complexidades e desafios da infraestrutura assim agenciada, tratarei de uma dinâmica dupla que ocorre na dahira. Sendo uma forma de organização religiosa, ela é caracterizada por um forte cuidado mútuo entre seus membros e com a organização em si, e sua estrutura se entende como uma ação coletiva da própria religião muçulmana e murid. De um lado, isso significava que necessidades complexas e urgentes sempre se resolviam a partir da dahira. Independente das condições individuais dos membros da dahira, em uma emergência ou, de forma mais ampla, em uma questão social, todos participavam da solução, normalmente com uma contribuição financeira. Nos raros casos de falecimentos e enfermidades graves, por exemplo, juntava-se dentro de poucos dias o valor necessário para repatriar o corpo ou facilitar a viagem da pessoa para se tratar no Senegal. O responsável da dahira confirmou o que se percebia facilmente: só as dahiras, por serem vinculadas à crença, têm essa força ${ }^{30}$. Em um compromisso de longo prazo, a dahira Norou Darayni igualmente tomava conta de seu membro mais velho, um homem por volta dos setenta anos, que emigrou já idoso. Respeitando sua decisão de permanecer como imigrante, além das ajudas diárias, o coletivo facilitou em 2016 sua última viagem para descansar com a família no Senegal. É preciso esclarecer que,

\footnotetext{
${ }^{29}$ HEIL, Tilmann. Perder, só perder.

${ }^{30} \mathrm{Na}$ minha pesquisa com outros grupos de senegaleses na Espanha, associações de pessoas do mesmo vilarejo, bairro ou cidade tinham uma capacidade parecida.
} 
embora contribuíssem com essas coletas, a maioria dos membros da dahira não conseguia juntar economias próprias para viajar a seu país ou só o fazia com muita dificuldade.

Especialmente na migração de senegaleses da confraria murid existe uma forte conexão com a religião. Tal vínculo construiu-se a partir das experiências do guia religioso murid Cheikh Ahmadou Bamba Mbacké durante seu exílio forçado pelo colonizador francês, nas décadas 1890 e 1900, e por meio do crescimento constante da rede murid em todas as partes do mundo ao longo das últimas décadas. Dois eventos ocorridos em 2016 e 2017 demonstraram o crescimento e a profissionalização da dahira em Niterói e o cuidado que seus membros têm com a religião.

Um momento de alegria e orgulho foi a primeira visita do marabout Mame Mor Mbacké no Rio de Janeiro, em 2016. Denominado o marabout da diáspora, ele circula em todo o mundo incorporando a parte mais representativa da rede global da confraria murid. É o marabout mais reconhecido, porém muitos outros membros menos conhecidos da família do fundador da confraria, Cheikh Ahmadou Bamba Mbacké, também viajam aos lugares onde se encontram seus discípulos. Coletam as contribuições dos fiéis às atividades do próprio marabout e às instituições da confraria no Senegal. Ao mesmo tempo, os marabouts cuidam do bem-estar religioso e moral dos discípulos. Embora vários petits marabouts (pequenos marabouts, literalmente) já tivessem colocado o Rio de Janeiro em seus roteiros, foi a primeira vinda do Mame Mor Mbacké que marcou o momento da inclusão da cidade na lista de lugares importantes da rede murid, o que significa um reconhecimento da maturidade das estruturas locais.

Além desse significado na confraria, a visita visibilizou importantes aspectos das infraestruturas que os senegaleses tinham estabelecido em um processo de autoconstrução, se relacionando e integrando elementos sócio-materiais da própria localidade urbana. Nesse momento, pela primeira vez, os senegaleses cariocas/fluminenses obtinham acesso ao Caminho Niemeyer de Niterói, um prestigiado conjunto arquitetônico público no centro da cidade, com teatros e salas abrigando parte da administração municipal. Meus interlocutores receberam Mame Mor Mbacké em um auditório de aproximadamente 200 lugares no prédio que abriga o acervo de Oscar Niemeyer. Além de cerimônias religiosas e uma discussão em português sobre a confraria murid, o marabout Mbacké evocou as virtudes do bom migrante senegalês ${ }^{31}$. O evento se tornou o primeiro marco da infraestrutura religiosa de chegada dos senegaleses no Rio de Janeiro.

Um segundo marco se realizou em 2017, quando os senegaleses voltaram ao Caminho Niemeyer, dessa vez com o màggal de Touba. O màggal é a principal

\footnotetext{
${ }^{31}$ Os discursos mereceriam uma análise própria que vai além do conteúdo desse artigo.
} 
festa religiosa murid. Celebra a volta do guia Cheikh Ahmadou Bamba Mbacké do exílio, acontecimento que se tornou a data da peregrinação dos fiéis para Touba, sua cidade santa no Senegal. Considerando pequena a sala fornecida pela prefeitura para a visita do marabout Mbacké, eles conseguiram acessar o maior espaço da composição, o teatro popular de Oscar Niemeyer. Em momento de plena crise econômica, os senegaleses na Região Metropolitana do Rio de Janeiro juntaram dezessete mil reais para convidar a cidade para a celebração. Distribuição de convites, horários bem definidos, um almoço para mais de 300 pessoas servido na área inferior do teatro, programação temática e um churrasco à noite demonstraram o crescente profissionalismo dos senegaleses. Apesar de uma forte participação dos senegaleses e de alguns brasileiros que atuavam regularmente de maneira significativa na infraestrutura de chegada senegalesa, os demais brasileiros participaram de forma aleatória, principalmente por haver comida e bebida de graça. Eram estudantes que se encontravam à tarde no espaço do Caminho, moradores de rua do centro da cidade e da rodoviária ao lado, além de alguns passantes. Naquele dia, os senegaleses trataram todos da mesma forma, como mencionou uma brasileira casada recentemente com um senegalês, algo que ela achava excepcional no cotidiano de exclusão e discriminação das pessoas mais humildes e marginalizadas no Brasil.

E assim a dahira, fundada por um grupo de cinco pessoas reunidas em um quarto de uma casa particular, conseguiu celebrar uma festa religiosa dentro de um teatro público no Caminho Niemeyer, no centro de Niterói, dez anos depois de sua criação. Os dois eventos mostram o dinamismo da chegada à Região Metropolitana do Rio de Janeiro, da autoconstrução e da interação com a cidade. São exemplos de como as infraestruturas dos recém-chegados lentamente tomam conta do espaço urbano, impactando-o. Exemplificam um novo agenciamento contribuindo à vida urbana a partir da chegada de migrantes. Para 2018, a dahira planeja celebrar em Niterói a Journée Khassida, um dia dedicado aos recitais e cantos religiosos. A terceira edição no Brasil da Journée Khassida, depois de ter sido realizada em Porto Alegre e Caxias do Sul, simboliza a maturidade das estruturas da dahira local. Porém, vale pesquisar os outros elementos cofundadores da infraestrutura de chegada dos senegaleses no Rio de Janeiro para entender melhor as dinâmicas e os desafios enfrentados.

\section{Interdependências polivalentes na infraestrutura}

Para entender algumas das especificidades do crescimento e das oportunidades que os senegaleses recém-chegados obtiveram ao longo dos últimos anos no Rio de Janeiro, precisam-se analisar todos os elementos da crescente infraestrutura de chegada. Além da dahira, um importante elemento é a Associação de Residentes Senegaleses no Rio de Janeiro, outra instituição de base que os senegaleses fundaram. Depois da primeira e malsucedida 
iniciativa de criar uma associação em 2005, a atual associação foi fundada em 2014 com a eleição de uma presidenta e seu comitê. Diferente da dahira, a associação se define como uma organização nacional e diaspórica, em que qualquer senegalês pode participar. Com essa iniciativa, buscava-se separar os assuntos sociais e religiosos dos assuntos ligados formalmente à migração e às relações com instituições políticas e administrativas.

A visita da nova embaixadora senegalesa no Rio de Janeiro em 2017 marcou o ponto alto da associação. Logo em seguida, um processo coletivo de regularização foi iniciado pela presidenta da associação em colaboração com a Caritas, a principal instituição de atendimento de solicitantes de refúgio. Juntas prepararam a documentação para a defensoria pública no Conselho Nacional de Imigração (CNIg), o que resultou na regularização da situação migratória da maioria dos mais de duzentos casos apresentados. Em uma iniciativa anterior no mesmo ano, a associação havia trazido uma equipe da embaixada senegalesa e um representante do governo senegalês para o espaço da dahira em Niterói de modo a facilitar os pedidos de passaportes novos nos casos de perda e expiração. Esse processo foi um esforço coordenado entre todas as associações senegalesas do Brasil e Argentina. A equipe percorreu várias localidades com forte presença senegalesa.

A boa organização coletiva aparece como ponto fundamental para agilizar esses processos. Para entendê-la, é preciso detalhar as interações e interdependências entre a associação e a dahira murid. Sendo as duas organizações-chave da infraestrutura analisada, por meio delas se pode compreender grande parte de sua dinâmica cotidiana. Apesar de as competências serem claramente definidas e separadas, existiam várias sobreposições. Primeiro, os membros mais ativos da dahira ocupavam postos no comitê da associação. Ainda que essa acumulação de cargos fosse proibida, a agilidade e visibilidade de certas pessoas dessas instituições resultavam em sinergias nos processos, embora gerassem críticas de pessoas que gostariam de uma divisão mais rígida. Além disso, a associação usava o espaço da dahira para as reuniões e para a preparação de suas atividades, como aconteceu no caso do esforço de regularização coletiva e no caso da comissão diplomática de passaportes. Apesar de os críticos dessa falta de divisão se manifestarem com frequência, minha análise aponta para o fato de que essas sinergias são essenciais para a infraestrutura trabalhar em favor dos recém-chegados e para que seus elementos sobrevivam em um contexto desafiador.

Na configuração atual, em momentos difíceis a associação dependia da estrutura da dahira. Desde sua fundação, ela passava por crises de legitimidade e representatividade. Um fator relevante nesse processo foi ela não ter conseguido a legalização como associação e ter perdido uma parte das contribuições dos membros. Enquanto na dahira as contribuições se fazem na base da confiança 
e dos preceitos religiosos, no caso da associação os senegaleses desconfiavam com frequência da prestação de contas e se negavam em seguida a pagar a taxa de associação. Nesses momentos, o apoio e as explicações dos líderes religiosos locais ajudavam a comunicar a importância e atuação da associação e advogavam por sua sobrevivência.

Mesmo assim, a associação e os membros de seu comitê desempenhavam um papel importante na vida social dos recém-chegados. Além da questão do status migratório e dos passaportes, a associação conseguiu o acesso ao Caminho Niemeyer para as festas da dahira nos últimos anos graças a seus contatos na prefeitura de Niterói. Sabendo que, como grupo religioso, não teriam conseguido esses espaços com a mesma facilidade, foi a associação que negociou o acesso. Ambos procuraram uma estratégia de comunicação que acentuasse aspectos culturais e nacionais baseados nas relações complexas entre a nação senegalesa e a confraria murid. Por exemplo, a conferência em português durante as celebrações do màggal focou na resistência pacífica de Cheikh Ahmadou Bamba Mbacké contra a colonização, parte da narrativa nacional senegalesa. Sua importância e apreciação por grande parte dos senegaleses, sejam murids ou não, se manifestaram também nas contribuições com os custos dos eventos por pessoas normalmente não envolvidas na dahira.

A interdependência dinâmica dos elementos da infraestrutura de chegada, aqui discutida no exemplo da relação dahira-associação, também se reproduz em relação a outros elementos, como a dahira tijan ${ }^{32}$, os senegaleses sem vínculo oficial à dahira ou à associação, o consulado senegalês, além dos professores e profissionais senegaleses que, na maioria dos casos, chegaram ao Rio de Janeiro nos anos 1990 e 2000.

Os discípulos tijans, menos numerosos do que os murids, começaram o processo de fundação de sua própria dahira em 2016. A sede é no Catete, bairro do centro do Rio de Janeiro. Essa dahira se beneficiava da participação de um professor-empreendedor senegalês que antes frequentava a comunidade murid em Niterói. Por ser accessível, esse professor fornecia informações relevantes sobre as oportunidades e o contexto local para os recém-chegados. Ele também participou ativamente nas conferências e festividades em Niterói. Por sua vez, os membros da dahira recitaram o Alcorão na casa dele por ocasião do Id, quando ele os convidou a comer. Sendo tijan, ele foi um dos fundadores da dahira tijan e fornecia sua galeria comercial para a realização dos encontros regulares, após a saída do espaço murid que os acolheu inicialmente. Ainda que isso não fosse explicitado verbalmente, nota-se um grande respeito mútuo entre as duas confrarias, porém, em alguns casos, também certa competição, tanto na prática religiosa quanto na forma da própria estrutura.

${ }^{32}$ A Tijaniyya é a segunda maior confraria senegalesa. 
Como se pode perceber, a relação entre diferentes grupos, gerações e camadas sociais de senegaleses é polivalente, igualmente enriquecendo e desestabilizando sua infraestrutura. No Rio de Janeiro, os vendedores de artesanato ocupavam com mais frequência um meio-termo entre a vida estabelecida dos profissionais e as dificuldades dos mais recém-chegados. Tanto o responsável da dahira quanto a presidenta da associação se dedicavam à venda de artesanato africano. Por motivos diferentes, ambos dispunham de contatos pessoais importantes e de um entendimento profundo da situação de chegada ao Rio de Janeiro, conhecimento que colocaram à disposição nas estruturas coletivas. Além disso, vários vendedores, tanto de artesanato quanto de outros objetos, disponibilizaram tais redes pessoais pelo coletivo. Em comparação, os professores e profissionais que chegaram ao Rio de Janeiro para estudar viviam uma realidade cotidiana muito diferente da dos vendedores de artesanato africano e mais ainda da realidade dos vendedores ambulantes e trabalhadores da construção civil. Embora periodicamente estivessem presentes nos eventos coletivos, por vezes em funções-chave, continuavam desconhecidos pela maioria dos recém-chegados.

Ao analisar as redes pessoais, é possível compreender a presença de alguns brasileiros com um perfil diferenciado na festa do màggal e na recepção do marabout. Todos contribuíram com alguma competência específica ao funcionamento da infraestrutura de chegada, aumentando pontualmente sua eficácia e polivalência. Entre eles, se encontravam: uma representante da prefeitura de Niterói; mulheres empreendedoras e majoritariamente negras de uma rede da qual a presidenta da associação faz parte; o ex-presidente da associação muçulmana da mesquita sunita da Tijuca, que muitos senegaleses frequentam nas sextas-feiras; voluntários de diversos projetos sobre migração na região; e os responsáveis pelo projeto Museu Memorial Gamboa, onde foram recitados os poemas de Cheikh Ahmadou Bamba Mbacké depois de serem encontradas sepulturas de possíveis escravos muçulmanos. Uma pessoa com uma importância maior nas festas era a dona de um atacado de óculos, mercadoria central para todos trabalhando nas praias cariocas e fluminenses. Muitos dos vendedores ambulantes se relacionavam com ela chamando-a de "mãe". Uma grande parte dessas pessoas havia figurado em outras ocasiões e atividades dos senegaleses. Nos eventos de 2016 e 2017, representantes da Caritas, uma das instituições mais centralmente vinculadas à infraestrutura dos senegaleses, se desculparam posteriormente por sua ausência. Agentes dos serviços sociais da prefeitura também não foram encontrados na ocasião das festas. No entanto, eles atuavam dentro da infraestrutura nos casos pertinentes, geralmente mediados por algum membro das instituições coletivas.

Além da Caritas, agentes sociais e alguns funcionários da prefeitura e de instituições que atuam na chegada de migrantes e refugiados no Estado e 
na capital apareceram aleatoriamente, em vários momentos, e em diferentes níveis. Não surpreende, porém, que eles não tenham sido tão presentes, devido à relativa ausência de tais serviços especializados. "No Rio de Janeiro, poucas organizações trabalham com o tema da migração, e a atuação dos governos do Estado e do município é um pouco tímida para lidar com as novas demandas que vêm surgindo"33, constata Cooper. O presente estudo precisará ser continuado no futuro, quando essa situação mudar ou quando novos serviços tiverem surgido, a exemplo do Centro de Proteção a Refugiados e Imigrantes da Fundação Casa Rui Barbosa, aberto em 2017. Muito provavelmente, o que veremos é como a infraestrutura muçulmana de chegada criará pontes e acessará instituições, estruturas e pessoas-chave de uma forma dinâmica e pontual, como vimos nos exemplos dos grandes eventos da comunidade senegalesa em Niterói. Por isso, esperam-se mudanças rápidas e pouco previsíveis na situação de chegada, que perceberemos claramente também na dimensão virtual da infraestrutura em questão.

\section{Infraestrutura virtual}

Antes de concluir, gostaria de destacar que uma dimensão importante das infraestruturas de chegada é a inclusão das novas tecnologias de comunicação ${ }^{34}$. Grande parte das relações complexas analisadas acima se manifestavam e se reproduziam no mundo virtual. Mesmo sendo um dos mais velhos dos senegaleses, o responsável da dahira participava de ao menos quatro grupos de WhatsApp ${ }^{35}$ centrais para a infraestrutura de chegada. Além do próprio grupo da dahira, no qual se comunicavam somente assuntos internos, existe um grupo mais aberto chamado "Touba Brésil TV Rio de Ja[neiro]", no qual membros da associação e da dahira informam sobre assuntos de interesse dos residentes senegaleses do Rio de Janeiro. Ademais, o dieuwrigne recebia informações de um grupo de todos os dieuwrignes de dahiras no Brasil e de um grupo de muçulmanos no Rio de Janeiro. Apesar de esses grupos terem uma longa duração, no tempo em que desenvolvi minha pesquisa outros grupos com fins praticamente iguais apareceram e desapareceram. Reproduziam-se nesses grupos as dinâmicas tanto de concorrência e disputa quanto de negociação e reconciliação que já descrevemos acima.

Desde 2015, faço parte do grupo Touba Brésil e acompanho a riqueza, densidade e diversidade das informações divulgadas e comentadas, às vezes

\footnotetext{
${ }^{33}$ COOPER, Carolina, GenOVEZ, Carolina, MONTINARD, Mélanie, VIEIRA, Rosa. Um mosaico de atuações no atendimento ao migrante, p. 56.

${ }^{34}$ Cf. BRIGNOL, Liliane Dutra. Usos sociais das TICs em dinâmicas de transnacionalismo e comunicação migrante em rede; DUTRA BRIGNOL, Liliane, DREY COSTA, Nathália. Migração e usos sociais do Facebook.

${ }^{35}$ No Facebook, se reproduz uma dinâmica parecida.
} 
em quantidades impossíveis de se consumir. Além das informações fornecidas pelos comitês da associação e da dahira, o porta-voz da última, homem dedicado às notícias e à informação, sempre encaminha destaques de grupos senegaleses estabelecidos em outras localidades. Constatam-se três grandes categorias de informação. Primeiro, as comunicações sobre atividades da dahira e as matérias sobre importantes acontecimentos da vida religiosa do Senegal publicadas pelos membros. Segundo, as notícias sobre a situação do migrante e recém-chegado. É o caso recente do compartilhamento de matérias sobre a nova Lei de Migração e listas de nomes publicadas no Diário Oficial da União comunicando o resultado dos vários processos de regularização. Terceiro, informações mais gerais sobre o Rio de Janeiro e o Brasil, cruciais durante os megaeventos dos anos anteriores no Rio de Janeiro.

Além da troca de informações, a dinâmica do grupo mostra claramente outra característica desse elemento da infraestrutura. Apesar de parecer um modo de comunicação bastante igualitário e acessível, o controle social e a chamada dos participantes à ordem se manifestaram imediatamente quando os responsáveis pelo grupo de WhatsApp sentiram a necessidade de censurar matérias divulgadas. Tratavam-se, principalmente, de conteúdos comuns nas redes sociais brasileiras que violavam fortemente a ética existente entre a maioria dos migrantes senegaleses ${ }^{36}$. Por fim, na dimensão virtual reproduziam-se e alargavam-se as múltiplas dimensões da infraestrutura de chegada dos senegaleses muçulmanos no Rio de Janeiro e nela se compensavam algumas das dificuldades de comunicação, apoio e interação que surgiam por causa da geografia física e social da Região Metropolitana, que impossibilita encontros presenciais.

\section{Conclusões}

Tendo exposto as complexidades, interdependências e polivalências na chegada de senegaleses à Região Metropolitana do Rio de Janeiro, concluo em três partes. A minha proposta de pensar as experiências dos senegaleses a partir do conceito de infraestrutura de chegada permitiu falar de forma abrangente sobre os múltiplos elementos que fazem parte dessa realidade, das instituições religiosas e da associação diaspórica, incluindo o papel de certos indivíduos sejam pessoas comuns ou representantes de estruturas locais - e a dimensão virtual de suas interações. Perante a relativa ausência de infraestruturas estatais de migração na região e a riqueza de estruturas produzidas pelos senegaleses recém-chegados num processo de autoconstrução, se justifica abordar o fenômeno em termos de infraestrutura de chegada. Pontualmente se criaram conexões com estruturas e agentes ativos na localidade, que se tornaram

${ }^{36}$ HEIL, Tilmann. Negão, Angolano, Africano? Sou Senegalês, Porra! Challenges to Senegalese Migration Ethics in Rio de Janeiro. 
centrais para a realização de seus projetos de vida coletivos e individuais. Além disso, ao considerar as dimensões sócio-materiais, aspecto central na proposta teórica da infraestrutura, foi possível lançar um novo olhar sobre as instituições coletivas estudadas anteriormente em outras localidades ao longo do processo migratório senegalês. A abordagem contribui como uma forma promissora de refletir sobre os vários elementos, níveis e lógicas da infraestrutura de chegada que permitem representar a complexidade da situação atual dos migrantes.

No centro da infraestrutura de chegada presenciamos uma relação multidimensional entre a associação diaspórica e a dahira murid, separadas formalmente em favor de uma inclusão maior de recém-chegados. Além de se perceber certa precariedade da associação e uma estabilidade da dahira, pode-se notar o dinamismo entre ambas, o que no fim funcionou a favor dos recémchegados. Porém, contestações abertas e latentes, às vezes constrangedoras, também ocorrem. Desafios semelhantes e alguns inconvenientes apareceram nas relações entre os demais elementos da infraestrutura que permitiram uma visão mais ampla das potencialidades construtivas e destrutivas que se destacaram como características dessas infraestruturas de chegada ${ }^{37}$. Por sua maior estabilidade devido à devoção religiosa, a dahira se manifestou como o centro dessa infraestrutura muçulmana de chegada.

Por último, nesse trabalho discuti a realidade de uma parte dos habitantes do Rio de Janeiro e seus desafios que correria o risco de passar despercebida em estudos mais tradicionais sobre as precariedades urbanas. No entanto, vimos claramente nos eventos organizados pelos senegaleses que cada vez mais se produzem novas realidades na interação dos recém-chegados com iniciativas existentes, suas instituições, atores e tecnologias. Pesquisar as infraestruturas muçulmanas de chegada é uma forma de contribuir para revelar um aspecto ainda desconhecido da vida urbana do Rio de Janeiro hoje. Esse olhar enriquece nosso conhecimento sobre as multiplicidades e incoerências das regiões metropolitanas na atualidade.

\section{Referências bibliográficas}

ABREU, Maurício de A. Evolução urbana do Rio de Janeiro. Rio de Janeiro: Zahar, 1987. AMIN, Ash. Lively Infrastructure. Theory, Culture \& Society, v. 31, n. 7-8, 2014, p. 137-161.

BABOU, Cheikh Anta. Brotherhood solidarity, education and migration: The role of the Dahiras among the Murid Muslim community of New York. African Affairs, v. 101, n. 403, 2002, p. 151-170.

BRIGNOL, Liliane Dutra. Usos sociais das TICs em dinâmicas de transnacionalismo e comunicação migrante em rede: Uma aproximação à diáspora senegalesa no Sul do Brasil. Comunicação Mídia e Consumo, v. 12, n. 35, 2015.

${ }^{37}$ Cf. LANDAU, op. cit. 
CARTER, Donald Martin. States of grace: Senegalese in Italy and the new European immigration. Minneapolis: University of Minnesota Press, 1997.

COMITÊ NACIONAL PARA OS REFUGIADOS. Sistema de Refúgio brasileiro: Desafios e perspectivas. Brasil: Ministério da Justiça; Governo Federal, 2016.

COOPER, Carolina; GENOVEZ, Carolina; MONTINARD, Mélanie; VIEIRA, Rosa. Um mosaico de atuações no atendimento ao migrante: Contrastes entre Rio de Janeiro e São Paulo. In Coletivo Rede Migração Rio (org.). A presença do migrante no Rio de Janeiro: O olhar das instituições. Rio de Janeiro: Associação Scalabrini, 2016, p. 54-58.

CRANSTON, Sophie; SCHAPENDONK, Joris; SPAAN, Ernst. New directions in exploring the migration industries: Introduction to special issue. Journal of Ethnic and Migration Studies, v. 44, n. 4, 2018, p. 543-557.

DE BOECK, Filip; BALOJI, Sammy. Suturing the City: Living Together in Congo's Urban Worlds. London: Autograph ABP, 2016.

DELANDA, Manuel. A new philosophy of society: Assemblage theory and social complexity. London: Bloomsbury Academic, 2006.

DELANDA, Manuel. Assemblage theory. Edinburgh: Edinburgh University Press, 2016.

DELEUZE, Gilles; GUATTARI, Félix. A thousand plateaus: Capitalism and schizophrenia. Minneapolis: University of Minnesota Press, 2005.

DIOUF, Mamadou. The Senegalese Murid trade diaspora and the making of a vernacular cosmopolitanism. Public Culture, v. 12, n. 3, 2000, p. 679-702.

DUTRA BRIGNOL, Liliane; DREY COSTA, Nathália. Migração e usos sociais do Facebook: Uma aproximação à weddiáspora senegalesa no Rio Grande do Sul. REMHU, Revista Interdisciplinar da Mobilidade Humana, v. 24, n. 46, 2016, p. 91-108.

GLICK SCHILLER, Nina; ÇAĞLAR, Ayşe (eds.). Locating migration. Rescaling cities and migrants. Ithaca: Cornell University Press, 2011.

GRAHAM, Stephen; MCFARLANE, Colin (eds.). Infrastructural lives: Urban infrastructure in context. London: Routledge, 2015.

HARVEY, Penelope. The topological quality of infrastructural relation: An ethnographic approach. Theory, Culture \& Society, v. 29, n. 4-5, 2012, p. 76-92.

HEIL, Tilmann. Negão, Angolano, Africano? Sou Senegalês, Porra! Challenges to Senegalese Migration Ethics in Rio de Janeiro, no prelo.

HEIL, Tilmann. Perder, só perder: Vendedores senegaleses durante os jogos olímpicos no Rio de Janeiro. In TEDESCO, João Carlos; KLEIDERMACHER, Gisele (orgs.). A imigração senegalesa no Brasil e na Argentina: Múltiplos olhares, Porto Alegre: EST Edições, 2017, p. 229-254.

HERÉDIA, Vania Beatriz Merlotti (ed.). Migrações internacionais: O caso dos senegaleses no sul do Brasil. Caxias do Sul, RS: Quatrilho Editora, 2015.

HUI, Allison. The Boundaries of Interdisciplinary Fields: Temporalities Shaping the Past and Future of Dialogue between Migration and Mobilities Research. Mobilities, v. 11, n. 1, 2016, p. 66-82. 
LANDAU, Loren B. Conviviality, Rights, and Conflict in Africa's Urban Estuaries. Politics \& Society, v. 42, n. 3, 2014, p. 359-380.

LARKIN, Brian. The Politics and Poetics of Infrastructure. Annual Review of Anthropology, v. 42, n. 1, 2013, p. 327-343.

MCFARLANE, Colin. The city as assemblage: Dwelling and urban space. Environment and Planning D: Society and Space, v. 29, n. 4, 2011, p. 649-671.

MEEUS, Bruno; KAREL, Arnaut; VAN HEUR, Bas. Arrival infrastructures: Migration and urban social mobility. Basingstoke: Palgrave Macmillan, 2018.

OLIVEN, Ruben George. Urbanização e mudança social no Brasil. Rio de Janeiro: Centro Edelstein de Pesquisas Sociais, 2010.

PAIVA, Odair da Cruz. Territórios da migração na cidade de São Paulo: Entre a afirmação e negação da condição migrante. Idéias, v. 2, n. 1, 2011, p. 13.

RICCIO, Bruno. «Transmigrants» mais pas «nomades»: Transnationalisme mouride en Italie. Cahiers d'Etudes africaines, v. 46, n. 1, 2006, p. 95-114.

RICCIO, Bruno. Transnational Mouridism and the Afro-Muslim critique of Italy. Journal of Ethnic and Migration Studies, v. 30, n. 5, 2004, p. 929-944.

SAUNDERS, Doug. Arrival city: How the largest migration in history is reshaping our world. London: Windmill Books, 2010.

SIMONE, AbdouMaliq. People as Infrastructure: Intersecting Fragments in Johannesburg. Public Culture, v. 16, n. 3, 2004, p. 407-429.

SIMONE, AbdouMaliq. Relational infrastructures in postcolonial urban worlds. In GRAHAM, Stephen; MCFARLANE, Colin (orgs.). Infrastructural lives: Urban infrastructure in context. London: Routledge, 2015, p. 17-38.

TEDESCO, João Carlos; KLEIDERMACHER, Giselle (ed.). A imigração senegalesa no Brasil e na Argentina: Múltiplos olhares. Porto Alegre: EST Edições, 2017.

TONKISS, Fran. Cities by design: The social life of urban form. Cambridge: Polity, 2013.

VERTOVEC, Steven (ed.). Diversities old and new: Migration and socio-spatial patterns in New York, Singapore and Johannesburg. Basingstoke: Palgrave Macmillan, 2015.

XIANG, Biao; LINDQUIST, Johan. Migration Infrastructure. International Migration Review, v. 48, 2014, S122-S148.

Recebido para a publicação em 31.01.2018

Aceito para publicação em 11.04.2018

Received for publication in January 315t, 2018

Accepted for publication in April 11 1 th 2018

ISSN impresso 1980-8585

ISSN eletrônico 2237-9843

http://dx.doi.org/10.1590/1980-85852503880005207

(c) (i) This is an open-access article distributed under the terms of the Creative Commons Attribution License 